\title{
A polymorphic, thrombospondin domain-containing lectin is an oocyte marker in Hydractinia: implications for germ cell specification and sex determination
}

\author{
BRAHIM MALI ${ }^{1}$, R. CATHRIONA MILLANE², GÜNTER PLICKERT ${ }^{3}$, MARCUS FROHME ${ }^{1}$ and URI FRANK ${ }^{*}, 2$ \\ ${ }^{1}$ Molecular Biology and Functional Genomics, Technical University of Applied Sciences, Wildau, Germany, \\ ${ }^{2}$ School of Natural Sciences \& Martin Ryan Marine Science Institute, National University of Ireland, \\ Galway, Ireland and ${ }^{3}$ Institute of Zoology, University of Cologne, Germany
}

\begin{abstract}
We have identified a novel, multidomain, polymorphic lectin in the marine cnidarian Hydractinia echinata. The gene is expressed in oocytes and was therefore named CEL for cnidarian egg lectin. The predicted protein has an unusual domain architecture, consisting of variable numbers of thrombospondin type 1 domains, flanked by one $\mathrm{N}$-terminal and two C-terminal galactose binding lectin domains. The diversity of the gene's transcripts results from allelic polymorphism as well as alternative splicing. Hydractinia is dioecious and its sex has been reported previously to be genetically determined. We found intersexual colonies that were functional males, but had immature CEL-positive oocytes alongside mature sperm in the same gonads. Intersexuality was observed to be common in one population but not found in others. Hermaphroditic, self-fertile colonies were found in one locality; however, in these cases gonads contained either male or female gametes without mixed ones. Intersexuality that was considered to be a very rare event is apparently a more common phenomenon, at least in some populations. True hermaphroditism also occurs in this species. CEL can be considered as a marker for early oocyte differentiation and may play a role in germ cell specification and sex determination in cnidarians.
\end{abstract}

KEY WORDS: alternative splicing, hermaphroditism, Cnidaira, intersexuality

Specification of germ cells is a major theme in developmental and evolutionary biology. Depending on the animal group, germ line specification may either be controlled by inherited maternal factors, or by inductive signals (Extavour and Akam, 2003).

In many animals, a boundary between somatic and germ-line cells is formed after germ-line specification has occurred during embryogenesis. Somatic mutations are prevented by this mechanism to be transferred to the next generation. A different mechanism is found in basal invertebrates where germ cells are continuously formed throughout adult life from pluripotent stem cells that also give rise to somatic cells (Frank et al., 2009). The mechanisms for germ cell specification in these animals, and the anatomic location at which it occurs, are unknown.

An additional important question is sex specification. In mammals, this process occurs downstream of germ cell specification as a response to signals emitted by the gonadal somatic tissue (Kocer et al., 2009). In contrast, sex determination in cnidarians, at least in certain species, occurs upstream of germ cell specification, and is controlled by the stem cells rather than by inductive signals from somatic tissues. This is evident from experiments showing that transplantation of adult male stem cells to adult females recipients causes sex reversals (Müller, 1964). Hence, the gonads probably emit a signal that induces pluripotent cells of a defined sex to become gametes. The situation may be different in other cnidarians, where sex reversals occur naturally.

Hydractinia is a colony forming, clonal cnidarian. Two North Atlantic sibling species, $H$. echinata and $H$. symbiolongicarpus have been studied since decades, mainly in the context of development and allorecognition (Frank et al., 2001). Hydractinia's stem cells, called interstitial cells or i-cells, are pluripotent and are

\footnotetext{
Abbreviations used in this paper: CEL, cnidarian egg lectin; ISH, In situ
} hybridization, SNP, single-nucleotide polymorphism; TSP, thrombospondin.

*Address correspondence to: Uri Frank. University Road, Galway, Ireland. Fax: +353-9149-4526. e-mail: uri.frank@nuigalway.ie

Supplementary Material for this paper is available at: http://dx.doi.org/10.1387/ijdb.103063bm

Accepted: 23 June 2010. Final author corrected PDF published online: 21 January 2011

ISSN: Online 1696-3547, Print 0214-6282

(C) 2011 UBC Press

Printed in Spain 


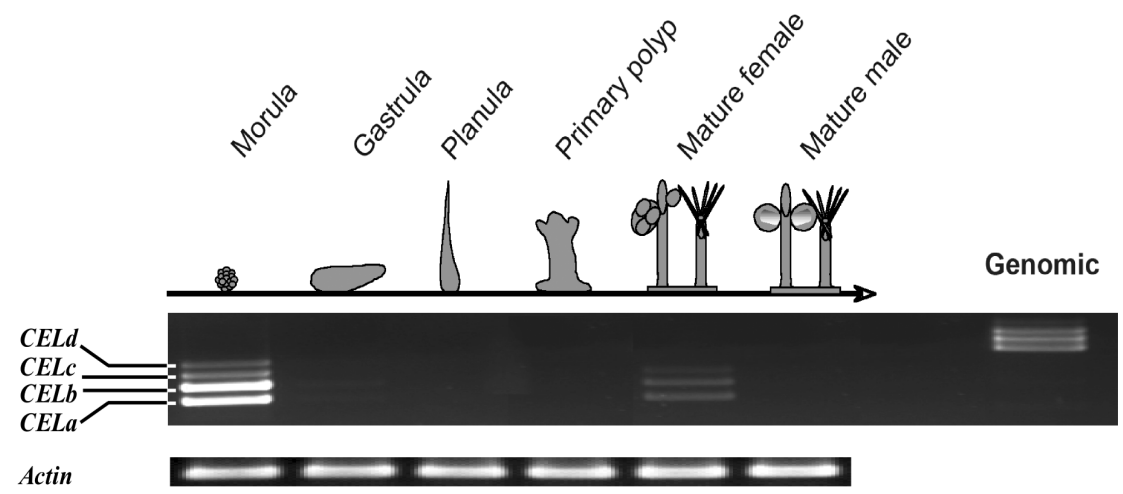

Fig. 1. Semi-quantitative RT-PCR on pooled total RNA and genomic DNA from animals sampled in the Sylt site. $R T$ T-PCR results show mRNA expression levels of CEL isoforms and Actin in four stages of developmental as well as in mature male and female colonies.

primarily located in the epithelial interstices of the gastrovascular system of the adults, called stolons (Müller et al., 2004). I-cells can migrate into newly growing parts of the colony where they differentiate into somatic and germ cells. Hydractinia is dioecious and its sex has been reported to be genetically determined with a few observed mutants that display intersexual phenotypes (Hauenschild, 1954).

Here we report a novel gene encoding a multi-domain, polymorphic and alternatively spliced lectin that also includes thrombospondin repeats from $H$. echinata. The predicted protein has a structure hitherto undescribed. The gene is expressed during oocyte differentiation but not in sperm progenitors, and its transcripts are still detectable in early embryos. As a female germ cell marker it revealed surprising data on sex specification in Hydractinia and we propose it to be a useful tool also for studies on germ cell specification. We have named the gene CEL for cnidarian egg lectin.

\section{Results}

\section{Identification and sequence analysis of the Hydractinia CEL cDNA}

By analyzing an expressed sequence tags (EST) database from the hydroid $H$. echinata we identified a cDNA clone (GenBank accession number C0536184) encoding a putative protein that included lectin domains and thrombospondin type 1 (TSP) re-
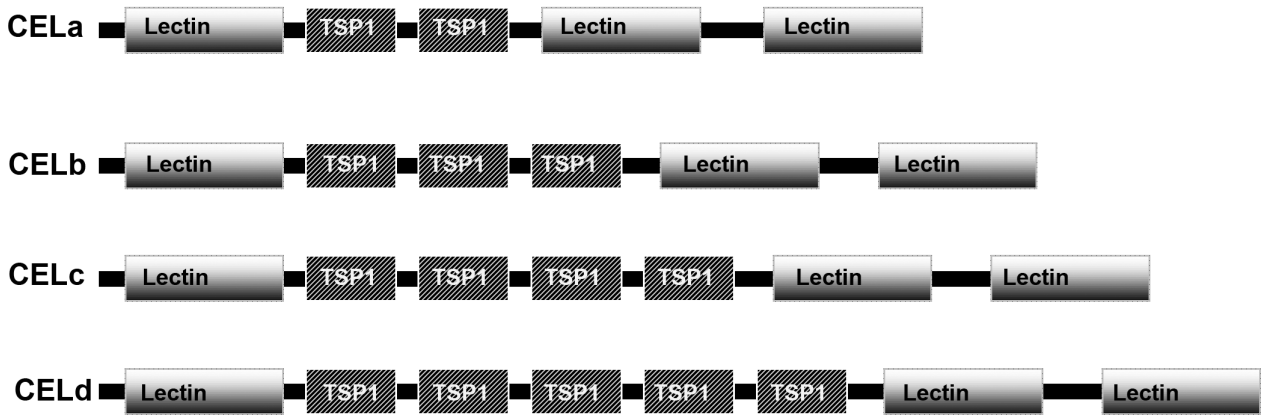

Fig. 2. Schematic representation of the domain structure of the various cnidarian egg lectin (CEL) isoforms. The isoforms differ in the number of TSP1 repeats. peats. We named the gene CEL for cnidarian egg lectin, due to its expression pattern (see below). The complete cDNA sequence of the gene was $1341 \mathrm{bp}$ long. It contained an open reading frame encoding 427 amino acid residues. Protein database searches at (http://www.cbs.dtu.dk/services/ SignalP/ and http://pfam.sanger.ac.uk/ search?tab=searchSequenceBlock) revealed that the predicted CEL had a signal peptide sequence at its $\mathrm{N}$-terminus, 2 thrombospondin type 1 repeats in the middle part, flanked by one galactose-binding lectin domain at the $\mathrm{N}$-terminus, and 2 other, tandem repeated lectin domains at the $\mathrm{C}$ terminus.

The primary structure of the galactose binding lectin domains of CEL is similar to the rhamnosebinding lectin (RBL) family. RBLs have structural features composed of two or three tandemly repeated carbohydrate recognition domains (CRD) of about 95 amino acid residues including eight conserved cysteines (Hosono et al., 1999). Initially discovered in sea urchin eggs, several forms of RBLs have been described in fish eggs (e.g. Hosono et al., 1999). This family of lectins is abundantly expressed in the ovary and egg of the steelhead trout.

The thrombospondin (TSP) 1 domain was first described in the thrombospondin protein where it is repeated three times. TSP1 repeats have later been identified in a wide set of secreted and membrane-bound proteins (for review see Adams and Tucker, 2000). The copy number of TSP1 in proteins varies from 1 to 18 . TSP1 has been reported to be a multifunctional domain, regulating several cellular responses. A possible role of fish thrombospondin in oogenesis has been proposed recently, based on its expression pattern in ovaries (Wu et al., 2009).

BLAST analysis showed that CEL is similar to Rhamnospondin from the congeneric hydroid, Hydractinia symbiolongicarpus (Schwarz et al., 2007), and to some predicted proteins from the sea anemone, Nematostella vectensis, and the freshwater polyp, Hydra spp. CEL also displayed similarity to numerous TSPcontaining proteins, such as hemicentins, which are not lectins, and to some lectins that lack TSP domains, such as RBL (Hosono et al., 1999). Rhamnospondin, in contrast, also contains the combination of TSP1 repeats and galactose binding lectin domains, but the overall structure of CEL is different. CEL, therefore, has a unique structure that has not been reported previously, but the combination of galectin binding domains with TSP1 repeats in a single protein may be cnidarian-specific.

\section{Cloning and analysis of CEL} isoforms by RT-PCR

We designed PCR primers spanning the entire cDNA of CEL and performed Semi-quantitative RT-PCR analysis of $C E L$ expression in different developmental stages. We performed the experiments with cDNAs from animals originating from two localities, Sylt, Germany; and Galway Bay, Ireland. The analysis revealed 


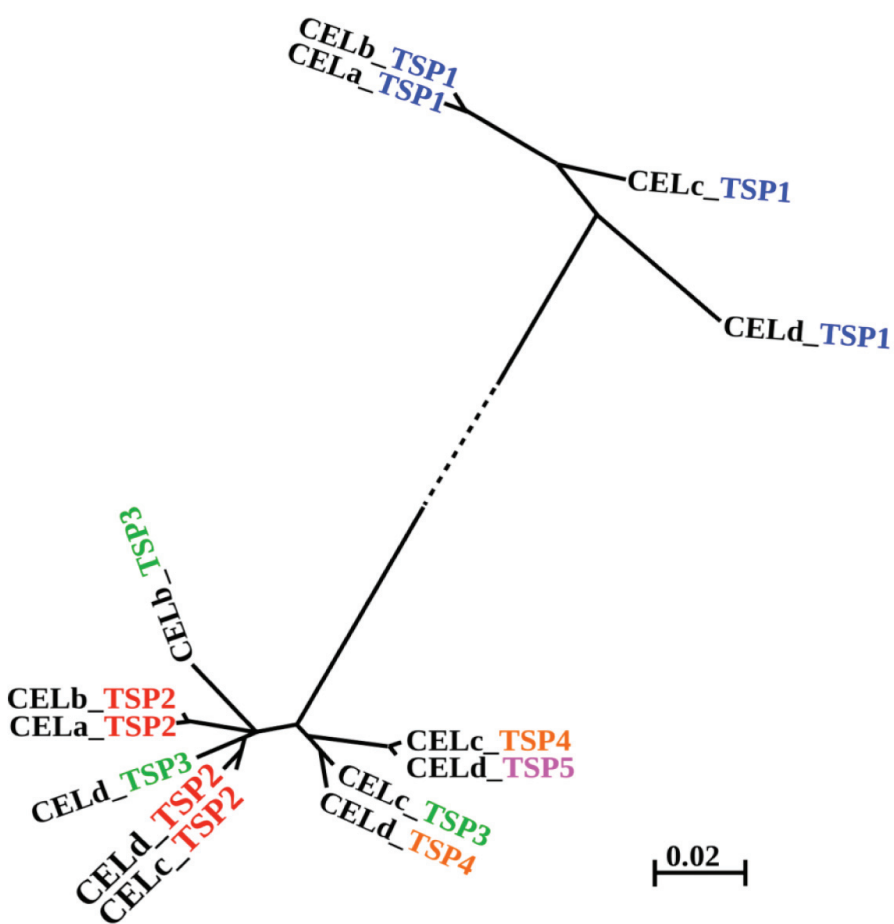

Fig. 3. Neighbor joining analysis of the thrombospondin1 (TSP1) domains, visualized as an unrooted tree. Bar indicates distance in units of nucleotide substitutions per site. Long branch is plotted with dashed line and represents 0.18 .

the presence of $C E L$ mRNAs in early embryos ( $<8 \mathrm{~h}$ post fertilization) and in mature female colonies. Levels of expression in mature male colonies, and in all other developmental stages of both males and females, were undetectable within 26 PCR cycles. Surprisingly, instead of one expected band at approximately $1.3 \mathrm{~kb}$, the PCR reactions yielded three additional products running at approximately $1.5,1.6$ and $1.8 \mathrm{~kb}$ in the Sylt animals (Fig. 1), but only 2 bands in the Galway Bay animals, at 1.3 and $1.5 \mathrm{~kb}$ (not shown). The bands were excised from the gels, cloned and sequenced. Sequence analysis of the bands revealed different numbers of encoded TSP repeats between the clones. We have named the isoforms as CELa (i.e. the original EST clone with 2 TSP1 repeats), CELb (3 TSP1 repeats), CELc (4 TSP1 repeats) and CELd (5 TSP1 repeats). CELd was the longest
cDNA sequence, comprising 1872 nucleotides including an open reading frame (ORF) encoding a 604-amino acid protein. The ORFs of CELC and CELb encoded 545 and 486 amino acid polypeptides, respectively (Fig. 2; Supplementary Fig. 1).

Alignment of the isoforms detected a total of 21 SNPs (singlenucleotide polymorphisms) that resulted in a change in the coded amino acid in 8 cases (Supplementary Fig. 1). Interestingly, in all SNP loci, CELa shared sequence with CELb, and CELc with CELd (Supplementary Fig. 1). This may indicate that CELa and $C E L b$ were alternatively spliced transcripts from one allele or gene, and CELC and CELd arose similarly from a different gene or allele (see below). To further examine the relationships among the CEL isoforms, their sequences were analyzed by neighbor joining and the analysis visualized by an unrooted tree (Fig. 3). The tree showed that the first TSP repeats of all CEL isoforms are more closely related to each other than to other repeats, whereas the other repeats did not show a clear relationship pattern, but were nevertheless highly similar (Supplementary Table 1).

\section{Genomic analysis of CEL}

To understand the occurrence of different $C E L$ transcripts, we extracted genomic DNA from animals sampled at three localities: Sylt (Germany), Galway Bay (Ireland) and Roscoff (France). Primers spanning the start and stop codons of the CEL gene were used in PCR reactions. Similar to the results of the cDNAs, described above, genomic PCR experiments revealed differences between animals originating at the Sylt site in Germany and those that came from Roscoff and Galway Bay (not shown). Pooled DNA from Sylt-sampled Hydractinia yielded a total of 3 distinct CEL bands (Fig. 1). The Roscoff and Galway Bay populations, in contrast, had only a single $C E L$ band, similar in size to the smallest band in the Sylt animals (not shown).

We have sequenced the entire genomic fragment of the Galway Bay animals from 800 bp upstream of the start codon until $18 \mathrm{bp}$ downstream the stop codon. The structure of the CEL gene from the Galway Bay population consists of 7 exons and 6 introns (Fig. 4). The seven exons correspond to the predicted structural domains of CELa and CELb, which, also based on their common SNP pattern, are probably derived from a single gene and obtained by alternative splicing. Exon 1 encoded the $\mathrm{N}$-terminal signal peptide. The individual lectin and TSP domains were each encoded by single exons. The nearly identical 5' and 3' UTR and introns 1-3 sequences from all localities, suggested that all the transcripts belong to one genetic locus. This locus is polymorphic

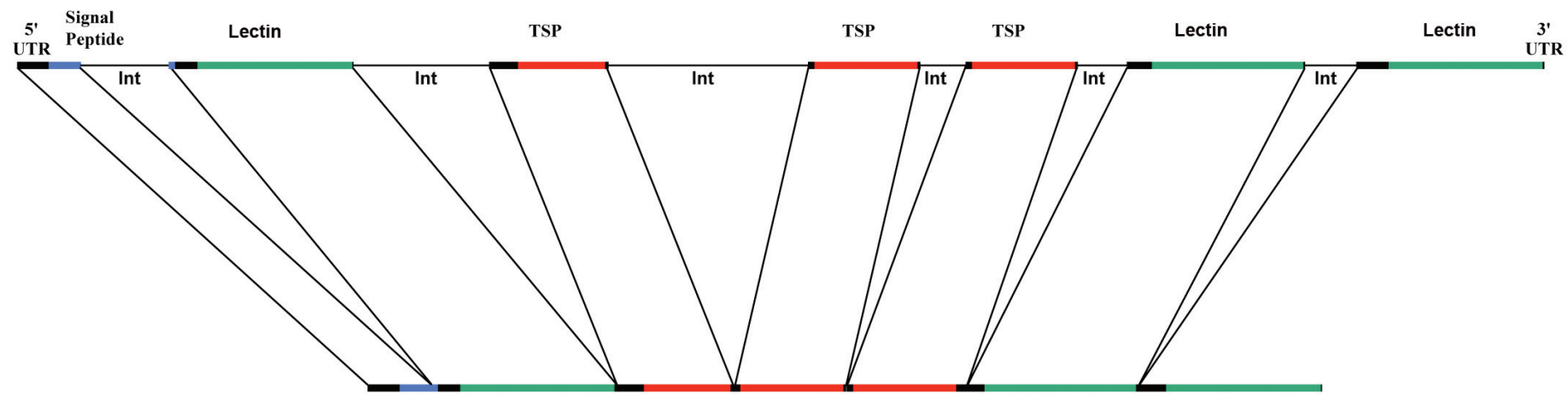

Fig. 4. Genomic structure of the Cnidarian egg lectin (CEL) gene from Galway Bay (Ireland). Green and red lines represent exons encoding lectins and thrombospondins (TSPS), respectively; Int, introns; UTR, untranslated region. Lower part represents the spliced CELb transcript. 
in the Sylt population (Fig. 1) but not in the sampled Galway Bay or Roscoff ones. The various cDNAs in Sylt population could therefore be the result of alternative splicing, allelic polymorphism, or a combination of both. Fig. 1 shows higher expression level of CELa and CELb, compared with the other two isoforms, which could be explained by variable allelic expression in the Sylt population, or preferential alternative splicing.

The differences in allele polymorphism between the sampling
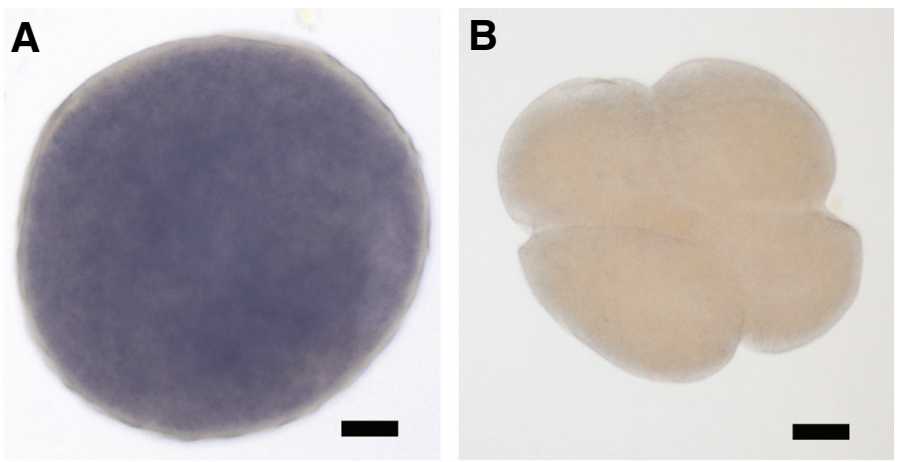

C

D
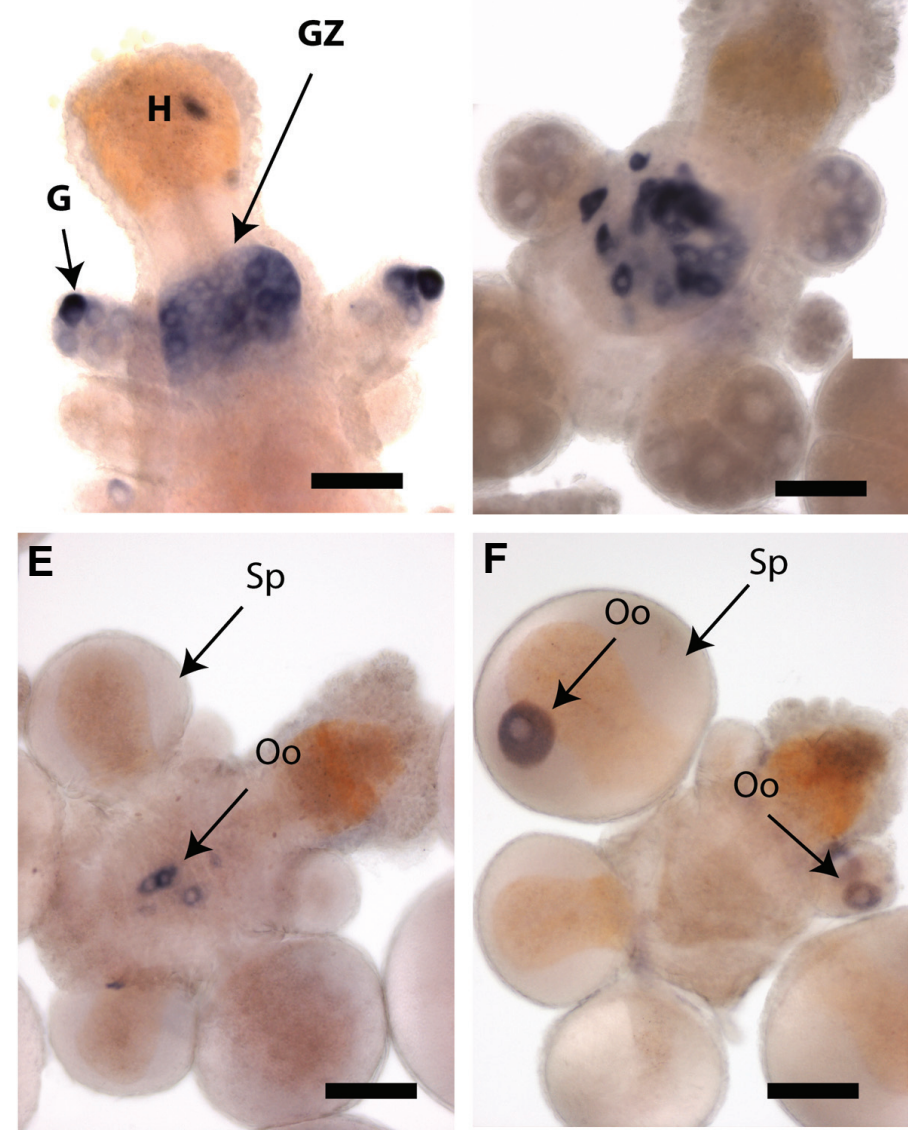

Fig. 5. In situ hybridization of Cnidarian egg lectin (CEL) in Hydractinia from Sylt. (A) Fertilized egg. (B) Four-cell stage, sense probe. (C,D) Female sexual polyps containing gonads with CEL expressing oocytes at different stages. (E,F) Male colonies showing some CEL-positive oocytes. H, head; G, gonad; GZ, germinal zone; Sp, sperm; Oo, oocyte. Scale bars $20 \mu \mathrm{m}$ in $(A, B) ; 50 \mu \mathrm{m}$ in (C-F). localities might have resulted from differences in the sampling methods. Animals from Sylt were sampled by dredging over a large area, while in Galway Bay and Roscoff, animals were sampled using SCUBA and skin diving from areas that were at least one order of magnitude smaller.

\section{Analysis of CEL spatial expression by in situ hybridization}

To determine also the spatial distribution of the CEL transcripts, whole mount in situ hybridization (ISH) analysis was performed at 7 different stages of Hydractinia development, including unfertilized egg, $3 \mathrm{~h}$ embryo, $24 \mathrm{~h}$ embryo, planula larva, $15 \mathrm{~h}$ post metamorphosis induction, primary polyp and male and female mature colonies. Sense and antisense RNA probes were generated from a cloned CELa cDNA fragment. The structure of the four-isoform cDNAs, having various numbers of overall similar TSP repeats (Supplementary Fig. 1; Supplementary Table 1), prevented a successful design of cRNA probes, which would selectively hybridize to only one of the four isoforms. Hence, a possible isoform-specific expression pattern could not be studied.

ISH revealed that in eggs and zygotes CEL mRNA was distributed uniformly (Fig. 5A). During the first cleavages, the ISH staining was still detectable, but the signal progressively faded, becoming undetectable after the late morula stage and in all other stages until the sexually mature colony. In mature colonies, CEL expression resumed but was restricted to only few cells. A Hydractinia colony is mainly composed of two polyp types, feeding polyps (gastrozooids) and sexual polyps (gonozooids), both emerging from the gastrovascular network, the stolons (Frank et al., 2001). Sexual polyps do not feed but contain the gonads. Stem cells (i-cells) migrate from the stolons into gonozooids where they become committed to germ cells and enter the gonads where differentiation into gametes is completed. ISH on mature female colonies stained early oocytes in the germinal zone of sexual polyps and in gonads (Fig. 5 C,D). Onset of expression appeared to be depending on location, as CEL positive cells were only observed close to the gonads and rarely in the head region, but never at the base of the polyp, or in stolons. It was possible to observe CEL-expressing, migratory oocytes as they move into the gonad (Fig. 5 C,D). The in situ signal gradually faded as oocytes matured. This suggests that $C E L$ expression commences just after oogenesis has started in germ cells before entering the gonads. It is the same region of the sexual polyp where i-cells stop expressing Vasa, a stem cell marker in Hydractinia, before they enter the gonad and complete oogenesis (Rebscher et al., 2008). Possibly, this is also the stage where i-cells lose pluripotency to become committed to gamete differentiation. Despite the RTPCR experiments on male colonies, revealing CEL expression below detection levels of 26 PCR cycles, we also performed ISH on 16 males, originating from Sylt, and 4 males, originating from Galway Bay. Surprisingly, in all 16 Sylt colonies, but not in the Galway Bay ones, there was at least one male sexual polyp containing a few CEL positive i-cells (Fig. 5 E,F). In some cases the ISH staining highlighted developing oocytes in the male gonads alongside mature sperm in a single gonad (Fig. 5F). Mature eggs, however, have never been observed in any of these male colonies, possibly due to inhibition of oocyte maturation by sperm-committed cells as suggested to be the case in Hydra (Bosch and David, 1986). No other CEL positive cells have been observed in any part of either male or female colonies, or indeed 


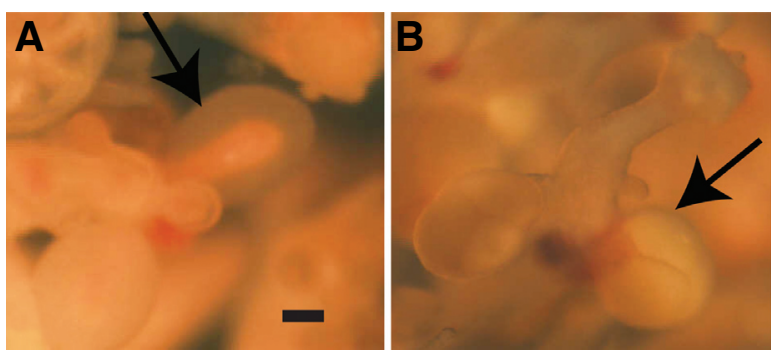

Fig. 6. Hermaphroditic colony. (A) Male. (B) Female. Arrows point to maturing gonads. Scale bar $100 \mu \mathrm{m}$

in any other developmental stage except of very early embryogenesis.

The apparently higher expression level in eggs and early embryos, as revealed by RT-PCR (Fig. 1), is an artifact as follows: RNA was extracted from whole mature colonies, in which the few CEL-positive oocytes were outnumbered by many $C E L$-negative somatic cells, as opposed to whole embryos where all cells were expressing $C E L$ at low levels.

\section{True hermaphroditic colonies}

We have also identified 4 animals, sampled in Galway Bay, which were predominantly females, but contained also fully developed male sexual polyps (Fig. 6). The gonozooids were either male or female and no mixed sex polyps, similar to some Sylt males, were observed. Self-fertilization within these hermaphroditic colonies resulted in embryos that developed normally until 2 days post fertilization and then died, possibly due to inbreeding.

\section{Discussion}

Intersexuality, expressed as single oocytes in functional male gonads, has been reported to be a rare genetic mutation in this species (Hauenschild, 1954), or be the result of allogeneic stem cell invasion of the opposite sex following natural or experimental grafting of male and female histocompatible colonies (Müller, 1967; Müller, 1964; Müller et al., 2004). Our results, using laboratory reared offspring from field-sampled animals and therefore non-chimeric, show that intersexuality is actually quite common in males, at least in the Sylt population. It may be rare or absent in other populations. Intersexuality was not evident in functional female colonies, but in the absence of an appropriate marker for early sperm differentiation, one cannot exclude single sperm-committed i-cells in normal female colonies. Self-fertilizing hermaphrodites were found in Galway Bay only; however, in these cases, male and female gametes were not observed in one gonad, or even one sexual polyp, but were restricted to individual polyps, either male or female. These field-collected animals could be chimeric, resulting from co-settlement of two, histocompatible larvae on the same shell. True hermaphroditism with both mature and functional sperm and oocytes has not been described in Hydractinia previously, but is known from other cnidarians, such as acroporid corals. Temperature-dependent sex was reported in the hydrzoan, Clytia (Carré and Carré, 2000), and fungiid corals undergo sex reversals naturally (Loya and Sakai, 2008). In the freshwater polyp Hydra, sex is determined by the stem cells.
Female stem cells can only produce oocytes, while male stem cells can produce both. Male stem cells in Hydra repress oocyte differentiation (Bosch and David, 1986). Hence, cnidarian sex determining mechanisms seem to be diverse, but the data presented here provide further evidence that sex in Hydractinia is controlled by the germ cells rather than by the somatic tissues of the gonads, as oocytes were developing alongside sperm in the same microenvironment.

CEL is a marker for the oocyte differentiation pathway and as such may also be used for further studies on the transition from pluripotent cells to germ cells, a process that occurs continuously in hydroids. The function of the gene product, which is predicted to encode a secreted thrombospondin domain-containing lectin, and the nature of the carbohydrates it binds remain elusive. CEL could be used by the released egg as sperm-recognizing and binding factor in analogy to the egg receptor for sperm binding in sea urchins (Zigler, 2008) or the ZP glycoproteins in the zona pellucida of the mammalian egg (Chiu et al., 2008). CEL may also have a role in the differentiation process from stem cell to oocyte. Alternatively, CEL might be an immune-related protein. The diversity of its transcripts, resulting from genomic polymorphism and/or alternative splicing, would be consistent with such a function.

\section{Materials and Methods}

\section{Animals}

Hydractinia echinata colonies, growing on gastropod shells that are inhabited by hermit crabs were collected from 3 different localities: One was on the Island of Sylt, Germany, the second site was Roscoff, France, and the third was Galway Bay, Ireland. The hermit crabs were removed and the hydroids cultured in artificial or natural seawater at $18^{\circ} \mathrm{C}$ under a 14:10 light:dark regime. Animals were fed brine shrimps nauplii 3-6 times a week. Under these conditions male and female colonies spawn nearly daily about an hour after the onset of light. Embryos were allowed to development for 3 days until the planula larva was competent to undergo metamorphosis. The larvae were induced to metamorphose into a primary polyp using a $3 \mathrm{~h}$ pulse treatment with $116 \mathrm{mM} \mathrm{CsCl}$ in seawater. Following the $\mathrm{CsCl}$ treatment, animals were positioned on glass cover slips on which they completed metamorphosis within $24 \mathrm{~h}$.

\section{Molecular biology}

All molecular biology work was done using standard protocols unless otherwise stated. Total RNA was isolated from different developmental stages by acid guanidium and phenol/chloroform extraction and reverse transcribed. The $C E L$ fragments from Sylt were amplified from cDNA of early embryos ( 3hours post fertilization) using primers starting at the methionine and the stop-codon, respectively, introducing restriction sites on both ends for cloning

F/ATGNcol: 5'CATGCCATGGATGGTGAATTTGCGATTA3';

R/TAAApal: 5'GATATGGGCCCTTATTTCACAATGCATCG3'. The fragments were cloned into the $\mathrm{pBlueScript-vector}$ and sequenced. Hydractinia actin was used as reference gene for semi-quantitative RT-PCR by using actin forward primer, 5'AAACCCTTTTCCAACCATCCTT3', and actin reverse primer, 5'TGGG CCAGATTCATCGTATTCT3'.

For the isolation of genomic DNA fertilized eggs were allowed to develop into primary polyps in the presence of $10 \mu \mathrm{g} / \mathrm{ml}$ tertacycline, replacing the water containing fresh antibiotic twice daily. Genomic DNA was isolated by SDS/ProteinaseK treatement and phenol/chloroform extraction. Nucleic acids were treated with a mixtured of $20 \mu \mathrm{g} / \mathrm{ml}$ RnaseA and 100 units $/ \mathrm{ml}$ RnaseT1 and the DNA was purified by two consecutive ethanol-precipitations in the presence of $1 \mathrm{M}$ ammonium acetate. 
Genomic CEL from Galway Bay was amplified from genomic DNA using primers from the 5' and 3' untranslated region: CELfwd: 5'GGTTACTTGTTCTTCCTGCAGTTTTG3'; CELrev: 5'ATCCACATGTTATTTGCAAGTATACGAC3'). The PCR-product was gel-purified and sequenced directly by primer-walking using primers located inside the introns. The 5' upstream region of the CEL gene was isolated by a modified version of the splinkerette protocol. The PCR product was also gel purified and sequenced directly. Amount and quality of extracted nucleic acids was assessed spectrophotometrically and by gel electrophoresis, respectively.

\section{RNA in situ hybridization}

For in situ hybridization, fragments of the coding sequence (300-400 bp) were cloned into pGEM-T or BlueScript vectors and sequenced. Next, the vector was linearized by restriction digestion and used as template for sense and anti-sense, DIG-labeled RNA probe synthesis. In situ hybridization and probe detection was performed according to standard protocols.

\section{Sequence analysis}

For functional annotation of the CEL transcripts, the program BLASTX was used to compare nucleotide sequences to the non-redundant protein database of the National Center for Biotechnology Information (NCBI). Conserved protein domains were searched in the Pfam and SMART databases. To identify a possible signal peptide, the CEL protein sequences were submitted to the SignalP server. Multiple alignment was performed using CLUSTALW and CLUSTALX with default settings. Neighbor-joining analysis of the $4 \mathrm{CEL}$ isoform sequences was performed with the programs NJPLOT (Perriére and Gouy, 1996).

\section{Acknowledgements}

We thank Fatemeh Shayeganfar, John Galvin and Albert Lawless for technical assistance. Werner A. Müller is kindly acknowledged for comments on an earlier version of the text. This work was funded by Science Foundation Ireland (SFI), grants Nos RFP2006-EEB050, 07/IN.1/B943 and $07 / I N 3 / B 943 / E C 07$ to UF.

\section{References}

ADAMS, JC and TUCKER, RP (2000). The thrombospondin type 1 repeat (TSR) superfamily: diverse proteins with related roles in neuronal development. Dev Dyn 218: 280-299.

EXTAVOUR, CG and AKAM, M (2003). Mechanisms of germ cell specification across the metazoans: epigenesis and preformation. Development 130: 58695884.

BOSCH, TC and DAVID, CN (1986). Male and female stem cells and sex reversal in Hydra polyps. Proc Natl Acad Sci USA 83: 9478-9482.

CARRÉ, D and CARRÉ, C (2000). Origin of germ cells, sex determination, and sex inversion in medusae of the genus Clytia (Hydrozoa, Leptomedusae): The influence of temperature. J. Exp. Zool. 287: 233-242.

CHIU, PC, WONG, BS, CHUNG, MK, LAM, KK, PANG, RT, LEE, KF, SUMITRO, SB, GUPTA, SK and YEUNG, WS (2008). Effects of native human zona pellucida glycoproteins 3 and 4 on acrosome reaction and zona pellucida binding of human spermatozoa. Biol Reprod 79: 869-877.

EXTAVOUR, CG and AKAM, M (2003). Mechanisms of germ cell specification across the metazoans: epigenesis and preformation. Development 130: 5869-5884.

FRANK, U, LEITZ, T and MÜLLER, WA (2001). The hydroid Hydractinia: a versatile, informative cnidarian representative. BioEssays 23: 963-971.

FRANK, U., PLICKERT, G. and MÜLLER, W.A. (2009). Cnidarian interstitial cells: the dawn of stem cell research. In Stem cells in marine organisms (Eds B. Rinkevich, and V. Matranga). (Heidelberg, Springer).

HAUENSCHILD, C (1954). Genetische und entwicklungsphysiologische Untersuchungen über Intersexualität und Gewebeverträglichkeit bei Hydractinia echinata Flem (Hydroz Bougainvill). Roux's Arch Entwicklungsmech 147: 1-41.

HOSONO, M, ISHIKAWA, K, MINEKI, R, MURAYAMA, K, NUMATA, C, OGAWA Y, TAKAYANAGI, Y, NITTA, K (1999). Tandem repeat structure of rhamnosebinding lectin from catfish (Silurus asotus) eggs. Biochim Biophys Acta 1472 668-675.

KOCER, A, REICHMANN, J, BEST, D and ADAMS, IR (2009). Germ cell sex determination in mammals. Mol Hum Reprod 15: 205-213.

LOYA, Y and SAKAI, K (2008). Bidirectional sex change in mushroom stony corals Proc R Soc Lond Biol 275: 2335-2343.

MÜLLER, W (1967). Differentierungspotenzen und Geschlechtsstabilität der IZellen von Hydractinia echinata. Roux Arch Entwicklungsmech 159: 412-432.

MÜLLER, WA (1964). Experimentele Untersuchungen über Stockentwicklung Polypendifferenzierung und Sexualchimären bei Hydractinia echinata. Roux Arch für Entwicklungsmechanik 155: 181-268.

MÜLLER, WA, TEO, R and FRANK, U (2004). Totipotent migratory stem cells in a hydroid. Dev Biol 275: 215-224

PERRIÉRE, G and GOUY, M (1996). WWW-query: An on-line retrieval system for biological sequence banks. Biochimie 78: 364-369.

REBSCHER, N, VOLK, C, TEO, R and PLICKERT, G (2008). The germ plasm component Vasa allows tracing of the interstitial stem cells in the cnidarian Hydractinia echinata. Dev Dyn 237: 1736-1745.

SCHWARZ RS, HODES-VILLAMAR, L, FITZPATRICK, KA, FAIN, MG, HUGHES AL, CADAVID, LF (2007). A gene family of putative immune recognition molecules in the hydroid Hydractinia. Immunogenetics 59: 233-246.

Wu, FR, Zhou, LY, Nagahama, Y, Wang, DS (2009). Duplication and distinct expression patterns of two thrombospondin-1 isoforms in teleost fishes. Gene Expr Patterns 9: 436-443.

ZIGLER, KS (2008). The evolution of sea urchin sperm bindin. Int J Dev Bio/52: 791 796. 


\section{Further Related Reading, published previously in the Int. J. Dev. Biol.}

See our recent Special Issue Placenta edited by Joan S. Hunt and Kent L. Thornburg at: http://www.ijdb.ehu.es/web/contents.php?vol=54\&issue=2-3

An organizing region in metamorphosing hydrozoan planula larvae - stimulation of axis formation in both larval and in adult tissue Melanie Stumpf, Britta Will, Karola Wittig, Jennifer Kasper, Benjamin Fischer, Jürgen Schmich, Stefanie Seipp and Thomas Leitz Int. J. Dev. Biol. (2010) 54: 795-802

Gonadal defects in Cited2 -mutant mice indicate a role for SF1 in both testis and ovary differentiation

Alexander N. Combes, Cassy M. Spiller, Vincent R. Harley, Andrew H. Sinclair, Sally L. Dunwoodie, Dagmar Wilhelm and Peter Koopman

Int. J. Dev. Biol. (2010) 54: 683-689

Cloning and functional characterization of the intersex homologous gene in the pest lepidopteron Maruca vitrata

Daniela Cavaliere, Francesca Di Cara, Lino C. Polito and Filomena Anna Digilio

Int. J. Dev. Biol. (2009) 53: 1057-1062

Diverse miRNA spatial expression patterns suggest important roles in homeostasis and regeneration in planarians

Cristina González-Estévez, Varvara Arseni, Roshana S. Thambyrajah, Daniel A. Felix and A. Aziz Aboobaker

Int. J. Dev. Biol. (2009) 53: 493-505

Oyster sperm bindin is a combinatorial fucose lectin with remarkable intra-species diversity

Stevan A. Springer, Gary W. Moy, Daniel S. Friend, Willie J. Swanson and Victor D. Vacquier Int. J. Dev. Biol. (2008) 52: 759-768

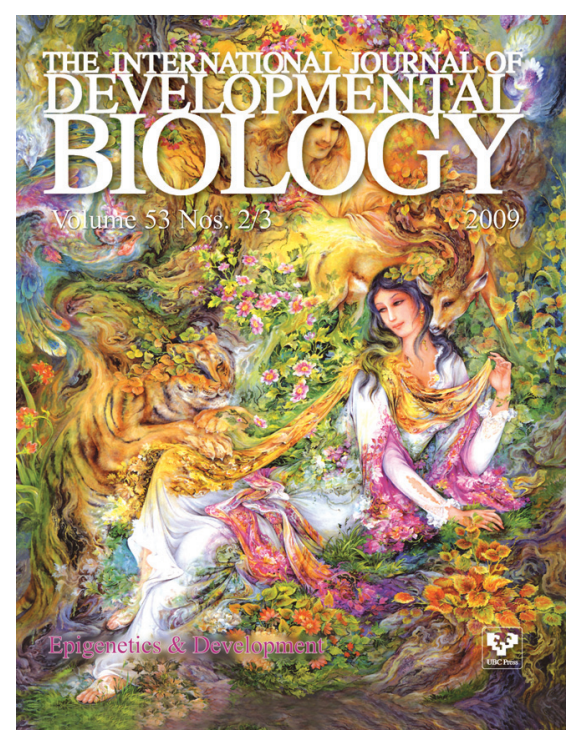

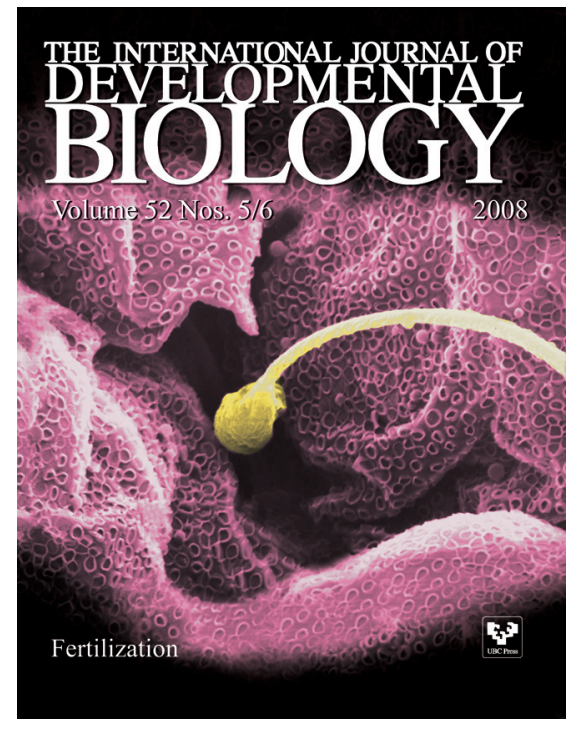

5 yr ISI Impact Factor $(2008)=3.271$

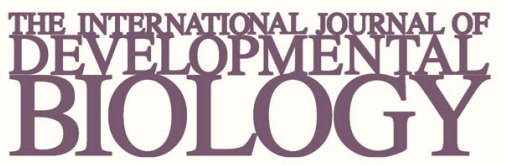

Volume 54 Nos. $6 / 7$

Special Issue
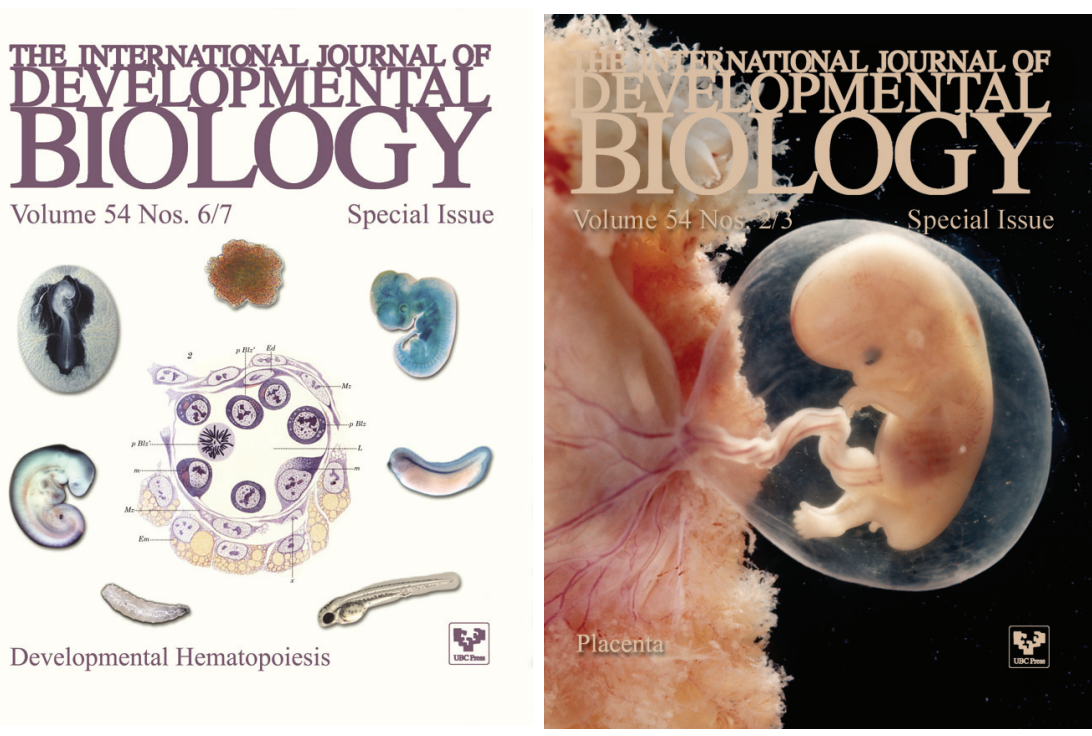